\title{
Percepções e atitudes de professores de escolas públicas e privadas perante 0 tema drogas ${ }^{*}$
}

\author{
Tatiana Cristina Diniz Ferreira ${ }^{1}$ \\ Zila van der Meer Sanchez ${ }^{2}$ \\ Luciana Abeid Ribeiro ${ }^{3}$ \\ Lúcio Garcia de Oliveira ${ }^{4}$ \\ Solange Aparecida Nappo ${ }^{5}$
}

FERREIRA, T.C.D. et al. Perceptions and attitudes among public school teachers towards the topic of drugs. Interface - Comunic., Saude, Educ., v.14, n.34, p.551-62, jul./set. 2010.

In Brazil, although teachers are considered potential agents for prevention of drug use, school-based prevention programs have not achieved the expected results over a period of more than two decades. Aiming to help in identifying the origin of the problem, teachers' perceptions and attitudes regarding this issue were evaluated. Twenty elementary and high school teachers in the city of São Paulo participated in this study, and semistructured interviews were conducted with them. Although these professionals recognized that they were opinion formers, they did not consider that they had sufficient skills to deal with this topic among their students, because of lack of information, interest or ability to deal with it. Regarding the information on this topic, it was found that there was low perception of risks associated with legal drugs. Given these results, it is suggested that schoolbased prevention programs should be reviewed and should involve participation by specialized professionals.

Keywords: Prevention. Teachers, Students. Qualitative research. Substance-related disorders. Schools.
No Brasil, apesar de os professores serem considerados como agentes potenciais para a prevenção do uso de drogas, há mais de duas décadas os programas escolares de prevenção não têm alcançado os resultados esperados. Com o intuito de auxiliar a identificação da origem do problema, foram avaliadas as percepções/ atitudes de professores sobre o tema. Participaram da pesquisa vinte professores do Ensino Fundamental e Médio da cidade de São Paulo, com os quais foram realizadas entrevistas semiestruturadas. Embora esses profissionais se reconheçam como formadores de opinião, não se consideram suficientemente habilitados para tratar do tema com seus alunos, seja pela sua falta de informação, interesse ou habilidade para abordar o assunto. Quanto à informação sobre o tema, verificou-se haver uma baixa percepção sobre o risco associado às drogas lícitas. Perante estes resultados, sugere-se que os programas de prevenção destinados ao ambiente escolar sejam revistos e tenham a participação de profissionais especializados.

Palavras-chave: Prevenção. Professores. Estudantes. Pesquisa qualitativa. Transtornos relacionados ao uso de substâncias. Instituições acadêmicas.
"Texto inédito, elaborado com base em estudo realizado no Centro Brasileiro de Informações sobre Drogas Psicotrópicas (CEBRID), Departamento de Psicobiologia, Disciplina de Medicina e Sociologia do Abuso de Drogas, Universidade Federal da São Paulo (Unifesp). Este trabalho recebeu o XIX Prêmio Pereira Barreto, com o título de Primeiro lugar na apresentação pôster, Categoria Saúde Coletiva, no XIII Congresso de Iniciação Científica da Unifesp. Financiado pela Fapesp e AFIP (Associação Fundo de Incentivo à Psicofarmacologia). Aprovado pelo Comitê de Ética em Pesquisa do Hospital São Paulo, Unifesp. ${ }^{1-5}$ Departamento de Psicobiologia, Universidade Federal de São Paulo. Rua Botucatu, 862, $1^{\circ}$ andar. São Paulo, SP, Brasil. 04.023-062. zila@psicobio.epm.br 


\section{Introdução}

A mais recente publicação epidemiológica de representatividade brasileira, sobre o uso de drogas por estudantes do Ensino Médio e Fundamental, mostrou um cenário que merece atenção. As drogas lícitas, representadas pelo álcool e pelo tabaco, têm um papel de destaque no consumo entre os adolescentes, tendo sido consumidas, respectivamente, por 44,3 e 9,9\% dos adolescentes, no mês anterior à pesquisa. Já as ilícitas foram consumidas, alguma vez durante as suas vidas, por quase $1 / 4$ dos adolescentes estudados. Nesta categoria, as mais consumidas são os inalantes, os quais foram utilizados por 15,5\% dos alunos investigados (Galduróz, Noto, Carlini, 2004). Outro estudo, ainda mais atual, porém só investigando o comportamento em relação ao consumo de álcool, evidenciou que quase metade dos brasileiros, entre os 14 e os 17 anos, beberam três ou mais doses de álcool em uma ocasião, tendo $16 \%$ deles, pelo menos uma vez no ano anterior à pesquisa, chegado a consumir mais de cinco doses (Laranjeira et al., 2007).

Assim, a questão do uso de drogas entre os estudantes é, sem dúvida, um tópico de destaque na saúde pública e na educação.

Em relação às estratégias educacionais para conter o abuso de drogas, nota-se que, na percepção coletiva, é fundamental a existência de ações cujo caráter seja preventivo e que estas sejam desenvolvidas por professores dos Ensinos Fundamental e Médio (Armelin, 1999). A Legislação Brasileira sobre o Uso de Drogas, mesmo havendo sofrido modificações ao longo das décadas, sempre regulamentou a formação continuada de professores na área de prevenção ao uso de drogas, e a implantação de projetos pedagógicos nos ensinos público e privado (Moreira, Silveira, Andreoli, 2006a; Mukoma, Flisher, 2004; Bizzotto, Rodrigues, 1997).

Sabe-se que os professores dos Ensinos Fundamental e Médio são considerados agentes da prevenção por serem potencialmente importantes veículos de formação e de informação sobre as drogas. Neste contexto, Moreira, Silveira, Andreoli (2006b) revelaram a importância dos discursos, das atitudes e dos comportamentos dos professores frente aos alunos, visto que estes constituem uma população em situação vulnerável (Sodelli, 2010). Também Freire (1996, p.24), em Pedagogia da Autonomia, valorizou o papel do professor ao afirmar que "gestos aparentemente insignificantes [dos professores] podem valer como força formadora do educando".

Além disso, o Ensino Fundamental e o Médio englobam a fase da adolescência, etapa de transição entre a infância e a idade adulta, na qual os indivíduos incorporam padrões de referência aos seus comportamentos, os quais servirão de base para a definição das suas personalidades (Sanchez, Oliveira, Nappo, 2005; Burt, 2002; Scivioletto, Morihisa, 2001). Nesta fase, o aluno expõe-se mais, porém responde bem às intervenções contextualizadas, especialmente nos seus contextos dominantes, como a escola e os seus pares (Schenker, Minayo, 2005), o que leva a valorizar as possíveis intervenções que partam dos professores.

Apesar da relevância do papel do professor, há mais de duas décadas os programas de prevenção que envolvem os profissionais citados não vêm obtendo a eficácia esperada (Faggiano et al., 2005; Mukoma, Flisher, 2004; Carlini-Marlatt, 2001; Soares, Jacobi, 2000). Nicastri e Ramos (2001) enfatizaram o papel crucial da informação como medida preventiva contra o abuso de drogas entre os adolescentes e os jovens. Estes pesquisadores destacaram que a informação deve ser veiculada com cautela, e de uma forma que, ao invés de prevenir o consumo de drogas, não desperte a curiosidade desses jovens pelo referido consumo.

Sodelli (2007) mostrou que os professores, apesar de compreenderem a importância da prevenção às drogas como sendo um trabalho necessário, têm tendência a não assumir esta tarefa, relegando-a a outros profissionais ditos mais especializados. O mesmo autor apontou que os cursos de formação dos professores para a prevenção não estão sendo capazes de promover alterações comportamentais e de valores nos professores, como também não conseguem fazer com que eles se sintam mais preparados para assumir a tarefa preventiva na escola (Sodelli, 2007).

Cruz (2002), por sua vez, salientou que os fracassos dos programas institucionais de prevenção estão relacionados aos discursos inadequados dos professores, os quais não respeitam as características psicológicas e sociais dos estudantes. 
Apesar destas informações oriundas da literatura científica, ainda é necessário investigar os fatores que melhor descrevem o pensamento coletivo dos professores dos Ensinos Fundamental e Médio, assim como a sua relação com estes discursos. O presente estudo qualitativo teve como proposta investigar como os professores dos Ensinos Fundamental e Médio da cidade de São Paulo percebem, agem e discursam em relação ao tema das drogas e dos seus usuários, considerando as suas percepções (suas ideias e imagens), as suas atitudes (como procedem) e as suas opiniões (como avaliam os fatos) sobre o referido tema.

\section{Método}

Optou-se por utilizar a abordagem qualitativa visto que esta permite a identificação dos valores, das crenças, das opiniões e dos comportamentos dos entrevistados. Este método de pesquisa permitiu compreender, em profundidade, a visão dos professores sobre o tema "drogas", de acordo com os seus próprios conceitos, revelados de forma aberta em seus discursos (Patton, 2002; Creswell, 1998; Taylor, Bodgan, 1998).

Como instrumento para a coleta de dados, foi utilizada a entrevista semiestruturada em profundidade (World Health Organization - WHO, 1994), direcionada por roteiro, na qual algumas questões foram previamente padronizadas e outras desenvolvidas ao longo do diálogo, de acordo com a necessidade de compreensão mais ampla de determinados tópicos. Um conjunto de questões básicas foi formulado a todo entrevistado, de modo a permitir comparar as respostas, além de reduzir a interferência do entrevistador e facilitar a organização e a análise dos dados (Patton, 2002; Creswell, 1998). A entrevista é considerada em profundidade por apenas ser dada continuidade ao roteiro quando a questão anterior é respondida nos seus mais profundos detalhes, e após o entrevistado ter esgotado o seu cabedal de colocações sobre o tema. A elaboração do roteiro foi baseada em entrevistas prévias com informanteschave, que são indivíduos que possuem um conhecimento especial da população em estudo (WHO, 1994). Nesta pesquisa, os informantes-chave foram duas psicólogas e cinco diretores de escolas públicas e particulares de diferentes bairros da cidade de São Paulo.

Foram realizadas entrevistas com vinte professores dos Ensinos Fundamental e Médio da cidade de São Paulo. As entrevistas tiveram a duração média de sessenta minutos, e foram conduzidas de acordo com técnicas para realização de entrevistas qualitativas adequadas. Todas as entrevistas ocorreram em local apropriado para esse tipo de intervenção (neutro e seguro), boa interação entre o pesquisador e os sujeitos pesquisados em clima descontraído, e a não manifestação da opinião ou ideias do entrevistador durante a entrevista (Minayo, 2004; Kvale, 1996). Com isso preservou-se o princípio de uma investigação qualitativa em que o fenômeno investigado é analisado sob a visão do entrevistado, isto é, segundo os seus valores, a sua compreensão e a sua vivência (Minayo, 2004). Além disso, as entrevistas foram anônimas e gravadas com consentimento prévio dos entrevistados, após assinatura do termo de consentimento, seguindo normas do Comitê de Ética em Pesquisa da Unifesp.

Os informantes-chave proporcionaram o contato dos pesquisadores com alguns professores da amostra, enquanto os demais componentes da amostra foram recrutados pela técnica da bola de neve (WHO, 1994), em que os primeiros de cada cadeia indicavam profissionais para serem entrevistados, os quais, por sua vez, indicavam outros professores para serem entrevistados, e assim sucessivamente. Estas cadeias foram constituídas por pessoas pertencentes a grupos diferentes no que diz respeito: às condições socioeconômicas, aos locais de moradia e de trabalho, à formação acadêmica (portanto, à disciplina ministrada), à idade e ao gênero. Não existiu nenhum tipo de contato entre os componentes das diferentes cadeias. Esta estratégia tentou assegurar uma maior heterogeneidade entre as cinco cadeias investigadas, permitindo a possibilidade de integrar à amostra perfis diferentes dos segmentos (Denzin, 2005).

As entrevistas foram gravadas, transcritas e identificadas por um código alfanumérico que significa, pela ordem: a inicial do nome do entrevistado, o sexo $(M=$ masculino; $F=$ feminino), a idade do entrevistado e o tipo de escola em que ele trabalhava $(P A=$ escola particular; $P U=$ escola pública e PAPU, caso o entrevistado trabalhasse tanto em escola particular quanto em pública) (Bryman, Burgess, 1999). 
As respostas foram analisadas com base na técnica de análise de dados qualitativos, proposta por Bryman e Burgess (1999) e aprimorada com conceitos da análise temática proposta por Minayo (2004), e análise de conteúdo proposta por Bardin (2004), cuja técnica consiste dos seguintes passos: leituras flutuantes que permitem o contato com o material e o estabelecimento de impressões sobre o fenômeno estudado; preparação do material, que consiste no desmembramento das entrevistas por temas e o reagrupamento das respostas conforme o tópico e a questão perguntada. As respostas referentes a cada uma das questões foram identificadas ao longo de cada uma das entrevistas e, com a ajuda de um software, desenvolvido especialmente para essa análise, criou-se um arquivo independente para cada item do roteiro. A partir daí foram feitas interpretações e inferências em relação ao tema investigado, de acordo com as informações obtidas nos discursos e baseadas nas análises de tendências das respostas.

O projeto foi aprovado pelo Comitê de Ética em Pesquisa da Universidade Federal de São Paulo/ Hospital São Paulo, seguindo todas as recomendações para pesquisas envolvendo seres humanos.

\section{Resultados e discussão}

\section{Dados sociodemográficos}

No que concerne aos dados sociodemográficos, os entrevistados foram caracterizados como: faixa etária entre os 24 e os 57 anos; tempo de atuação como professor, variando entre quatro e 39 anos; igual distribuição entre os trabalhadores das escolas públicas e das particulares; $75 \%$ mulheres; $65 \%$ católicos.

\section{Informações científicas dos professores sobre as diferentes drogas psicotrópicas}

\section{Tipo e origem da informação sobre as drogas}

A lei brasileira sobre drogas (Lei n.11.343/2006) preconiza que os professores possuam conhecimentos referentes a substâncias psicoativas para subsidiar a formação dos estudantes (Bizzotto, Rodrigues, 2007). Apesar disto, quase todos os professores entrevistados disseram não ter informações suficientes sobre drogas para transmiti-las aos seus alunos nem para conversar com eles sobre o tema, conforme o seguinte depoimento:

\footnotetext{
"Eu procuro me informar um pouco porque eu sou educadora e convivo com alunos que estão em contato com drogas e alunos traficantes, então tenho que estar informada. Mas eu não me sinto, assim, preparada. Tanto que eu nunca cheguei pra conversar com um aluno sobre o consumo de drogas ou sobre ele traficar, eu não tenho essa coragem". (VF41PU)
}

A análise do conteúdo dos discursos, sobre a participação dos entrevistados em algum evento relacionado a este tema, demonstrou que eles não estavam suficientemente capacitados para transmitir esse tipo de informação para os seus alunos, apesar de quase a metade dos professores ter afirmado que, buscando capacitação na área, já tinha participado de algum tipo de evento sobre drogas, como seminários, cursos, grupo de estudos, palestras e treinamentos. Porém, segundo eles, estas atividades forneceram apenas informações básicas sobre a temática, não continham informações relacionadas à didática por meio da qual os professores deveriam abordar o tema e, também, as informações não eram suficientes para formar um multiplicador sobre estas.

Foi observado, também, que os professores obtinham informações por leituras e vivências pessoais sobre o tema, o que contribui para a formação de uma opinião baseada no senso comum, levando a visões errôneas e deturpadas em relação às drogas. Um exemplo disto é o seguinte relato:

"O crack, segundo a base científica, é o resto de outras drogas compactadas, então são substâncias diferentes interagindo junto que vão causar um prejuízo maior ao cérebro". (EF29PAPU) 
Drogas lícitas são menos perigosas que as ilícitas

Embora seja uma ideia observada apenas nos depoimentos de alguns dos entrevistados, notouse que estes professores consideram as drogas lícitas menos perigosas do que as ilícitas, atribuindo a estas últimas um maior potencial deletério ao organismo. Este dado também foi observado por Del Rio e Alvarez (1995), os quais perceberam que a sociedade espanhola atribuía às drogas ilegais um potencial de dano à saúde muito maior do que aquele provocado pelo álcool e pelo tabaco. Moreira (2005), avaliando os conhecimentos e as atitudes dos coordenadores pedagógicos das escolas públicas de São Paulo, verificou que é mediano o conhecimento dos educadores sobre drogas, com melhor desempenho nas questões sobre as drogas ilícitas e menor desempenho nas questões sobre o álcool.

Esta percepção pode ser identificada por meio do relato mostrado a seguir:

"Olha, eu acho que o álcool e o tabaco seriam considerados drogas, mas eu acho que não seria aquela droga tão... Ela não muda o comportamento, eu acho que o tabaco não chega a mudar o comportamento do indivíduo assim, não é?". (FM48PA)

Talvez esta visão seja justificada pelo próprio consumo dos professores, já que quase todos fazem ou fizeram uso de drogas lícitas, enquanto somente alguns utilizaram drogas ilícitas.

\section{A falta de informação como fonte de medo em tratar o tema}

Os professores, por conta da falta de informação e do receio de não terem respostas para sanar as dúvidas dos estudantes, demonstram medo e incapacidade para lidar com a prevenção do uso de drogas, como pode ser visto nos trechos que seguem abaixo:

\footnotetext{
“Eu não me acho capaz de ficar criando discurso [de prevenção]. E pra falar a verdade eu posso até falar que eu não me acho capaz e nem acho que os professores são capazes pra fazer isso [programas de prevenção]". (CM38PAPU)

"Às vezes eu falo de maneira geral, mas eu não sei especificamente que órgão ataca, eu sei mais ou menos. [...] Eu não sou especialista". (RF29PA)
}

Fatores de risco para o início do uso de drogas: influência quase exclusiva do meio

Quando inquiridos sobre os fatores de risco para o início do consumo de drogas, quase todos apontaram para os sociais, ou seja, o meio em que vivem e a classe socioeconômica a que pertencem. A partir desta percepção, observou-se que, na opinião da maioria dos entrevistados, os estímulos externos são os responsáveis por fazerem as pessoas iniciarem o consumo de drogas. Isto implica duas realidades distintas. Na primeira, tal fato pode levar os professores a isentarem o usuário das suas responsabilidades, já que, na opinião deles, predomina a visão de que este indivíduo age por meio de influências indiretas que vêm de experiências externas. Assim, ele executa ações que não surgem da sua própria vontade e são determinadas por fatores extrínsecos à sua pessoa. Isto resulta em considerar que os usuários são indivíduos sem autonomia para tomarem as suas próprias decisões e, até mesmo, exercerem o seu direito de dizer não. Na segunda, no discurso desses professores, a visão de usuários tendo as suas ações sempre determinadas pelo meio social está relacionada a experiências negativas, como a desestruturação familiar e a instabilidade emocional. Em contrapartida, a caracterização dos indivíduos que não usam drogas como indivíduos que têm uma boa base familiar, estabilidade emocional e têm disponibilidade de informação parece ser bastante positiva, embora utópica, fugindo à realidade que hoje pode ser observada na nossa sociedade.

No entanto, os professores não parecem ter noção da dimensão multifatorial que influencia o consumo de drogas, detendo-se, quase que exclusivamente, no papel dos fatores externos ao adolescente, pouco citando fatores internos que interferem na sua decisão de consumir. Conforme Scivoletto e Morihisa (2001), há um consenso no meio científico de que o uso e o abuso de substâncias psicotrópicas é multifatorial (dimensão biopsicossocial), e que os principais fatores envolvidos são: a curiosidade, a obtenção de prazer, a influência do grupo, a pressão social, o 
isolamento social, a baixa autoestima e a dinâmica familiar. Neste contexto, as escolhas feitas pelo adolescente estariam sujeitas a inúmeros fatores externos e internos que, no balanço final, iriam gerar uma atitude diante do consumo de drogas.

\section{Professores como formadores de opinião}

Foi observada, em alguns relatos, uma grande preocupação, por parte dos professores, em não usar drogas (em geral lícitas) na frente dos alunos, visto que eles se sentiam como modelos/ referências para os mesmos, conforme se pode verificar por este depoimento:

"O meu vício não pode servir de mau exemplo pra eles, não é? Porque o professor, para aluno, é um espelho. Então o que eu fizer de errado, ele vai achar que pode fazer que é comum, que é normal". (CF38PU)

Em vista disto, nota-se que, para estes profissionais, o seu próprio consumo de drogas tinha uma conotação negativa, e eles evitavam propagar este comportamento. No entanto, esta postura não é consensual. Apesar da posição que ocupam, e mesmo cientes do fato de serem formadores de opinião, curiosamente existem professores que não possuíam essa preocupação, o que pode ser comprovado pela seguinte declaração:

"Com o pessoal maior de idade, nós saímos às sextas-feiras para um "happy hour" num bar qualquer. E eu fumo cigarro, tanto é que alguns criticam de vez em quando (risos). Eles não acreditavam que eu fumava. Aí eu falava: 'Eu sou o quê? Você acha que eu sou um E.T.?'" (MM52PAPU)

Outros ainda preferiram isentar-se completamente da responsabilidade como formador de opinião, transferindo a competência da educação sobre drogas totalmente para a família do aluno, conforme o depoimento abaixo:

\footnotetext{
“Não sou eu que vou ensiná-los ou não a fumar. Apesar de se ter uma idéia que na escola ele vai se deteriorar, [...] não é na escola que ele vai começar a fazer coisa errada. Quando ele chega pra nós ele já vem fazendo coisa errada dentro da casa dele". (TF46PAPU)
}

\section{O postura do professor quanto ao uso de drogas pelos alunos}

É importante ressaltar que a observação de indícios do uso de drogas pelos alunos resulta em posturas variadas por parte dos professores. Há aqueles que não fazem nada, pois têm receio de abordar o tema, não sabem como lidar com o assunto ou pensam que não têm, como uma das suas funções, a de alterar a conduta do aluno. Esta percepção pode ser melhor visualizada no seguinte discurso:

"Quem sou eu pra chegar junto?". (MM52PAPU)

Há também os que conversam com os alunos, encaminham para a coordenação e para a direção ou passam a abordar o tema em sala de aula após notar indícios de uso. Um deles disse achar que o trabalho do professor é muito limitado, não tem continuidade e que, às vezes, tinha a sensação de que não estava fazendo nada:

“Eu acho que cabe a gente, que é o adulto da escola, a gente estar de olho pra algumas coisas. [...] O nosso trabalho de professor é muito limitado. Porque você só faz isso, mas você não dá continuidade. [...] A impressão que eu tenho é que parece que tudo o que você faz é muito pouco, não é nada pra aqueles alunos, pra aquela molecada." (CM38PAPU) 
Estas respostas novamente trazem à tona atitudes e opiniões distintas entre os diferentes professores, fato que deveria ser considerado na realização dos programas de prevenção ao consumo de drogas, cuja aplicação é destinada às escolas. A maneira como cada professor trata o tema é peculiar. Essa distinção deve ser observada, sobretudo para que não se continue implementando programas de prevenção, cuja aplicação seja idealizada para ocorrer de maneira idêntica nas diferentes escolas, de diferentes bairros e classes sociais, e para ter a sua forma igualmente reproduzida por diferentes professores. A participação destes no projeto de execução, discussão e avaliação dos programas é fundamental.

\section{A prevenção na escola}

A maior parte dos entrevistados considerou que a escola tinha um papel fundamental a desempenhar na prevenção ao consumo de drogas. Afinal, ela possui um caráter de socialização, ou seja, de tornar possível o contato do jovem com realidades diferentes da sua e, a partir daí, fazê-los incorporar ideias, comportamentos e atitudes frente a determinadas situações. Em outras palavras, é na escola que as pessoas se tornam informadas e constroem as suas opiniões sobre determinados assuntos, o que, segundo os entrevistados, não poderia ser diferente em relação ao tema "drogas". discurso a seguir ilustra a ideia:

"A escola, como um templo do saber, [...] como um lugar onde parte da educação e parte da formação de caráter do aluno é feita, tem como dever elucidar e tentar ao máximo prevenir o uso abusivo de drogas." (DM24PU)

Os entrevistados relataram também que existiam dificuldades para que a escola conseguisse cumprir um papel preventivo em relação ao uso de drogas, pois os professores, os pais e a comunidade deveriam estar mais engajados na formação das crianças e dos adolescentes.

Em contrapartida, os professores demonstraram ter consciência de que a escola teria condições de desenvolver um trabalho que se destinasse à prevenção do uso de drogas, especialmente por possuir um espaço para isso, por ter contato direto com os adolescentes e por dispor de profissionais que poderiam ser preparados para executar esse tipo de ação.

Nóvoa (1999), há uma década, afirmou que os professores eram paradoxais, ou seja, possuíam um discurso retórico complexo no que dizia respeito ao que faltava nas escolas, mas, ao mesmo tempo, não se colocavam à disposição para mudar o quadro.

A maioria dos entrevistados relatou que eram desenvolvidas atividades preventivas em relação ao uso de drogas nas escolas em que eles trabalhavam, embora alguns deles não soubessem caracterizar como ocorriam essas atividades, e considerassem que o fato de falarem sobre o tema em sala de aula era uma forma de prevenção.

Tal abordagem do tema, em sala de aula, foi relatada por menos de uma quarta parte dos professores entrevistados. Parecia que o receio de possíveis represálias por parte do tráfico ou dos próprios alunos consumidores os assustava. Segundo esses profissionais, a droga poderia fazer parte do ambiente no qual o aluno vivia e ser um meio pelo qual ele sobreviveria financeiramente ou, ainda, ser a causa da sua dependência química. Esta opinião foi bem expressa pelo depoimento abaixo:

“Eu não entro no mérito de dizer 'Vamos fazer uma campanha de prevenção'. E eu vou Ihe explicar o porquê: porque isso é bater de frente com pessoas que seriam contra esse tipo de postura. Eu tenho colegas que já tiveram sérios problemas porque resolveram fazer uma campanha anti-drogas na escola [...]. Eu tenho experiência de amigas minhas que foram ameaçadas, que encontraram bilhetes no carro pedindo para parar, senão elas iriam ter que parar de qualquer forma." (MF37PU) 
Quando o professor decide tratar o tema "drogas" em sala de aula, a frequência desta atividade é variável, podendo ela ser realizada semanalmente em uma disciplina específica para isso, uma vez por ano ou somente quando os alunos questionam algum aspecto relacionado ao tema.

Isso demonstra a falta de engajamento de alguns professores em relação à implementação nas escolas de programas de prevenção ao uso de drogas. Dada a importância do assunto na área da Saúde Coletiva, é imprescindível que os profissionais que têm contato direto com o jovem - que é quem está mais susceptível a usar drogas pela própria característica da sua faixa etária -, sejam motivados a agirem como agentes de prevenção. Como o aluno dirige as suas dúvidas para o professor, a limitação deste em tais situações leva-o a tomar uma postura de autodidata frente à temática.

\section{Interesse dos alunos pelo tema}

$\mathrm{Na}$ opinião dos professores, os alunos estão bastante desinformados e curiosos em relação ao tema "drogas". Mais da quarta parte dos entrevistados considerou que os alunos estão bastante interessados em abordar assuntos que foquem o tema das drogas, e chegando, até mesmo, após participarem de atividades que os esclareçam sobre o tema, a apresentarem mudanças significativas no seu comportamento, conforme o depoimento que se segue;

“Às vezes eles ficam em casa buzinando, sabe? [...] Então sempre vêm as mães falando 'Ah, meu Deus! Depois que vocês fizeram essa campanha [de prevenção] ele não pára de me encher o saco'. E houve mães que mudaram o seu comportamento e que foram fumar fora de casa, sabe, pois a criança batia o pé dizendo que ela dentro de casa não fumava mais". (CF25PA)

Este depoimento reflete a importância e a influência do trabalho dos professores para a formação da opinião dos alunos. O aluno leva para casa aquilo que ouve na escola e, dependendo da forma como o assunto foi abordado, multiplica a sua opinião entre os familiares.

Alguns professores também relataram que havia alunos que se mostravam muito resistentes quando o tema era abordado, não sendo receptivos ao mesmo. Este perfil de comportamento observase em uma minoria, mas não pode deixar de ser levado em consideração quando da elaboração dos programas de prevenção.

Essa percepção reflete as sensações que os professores têm da repercussão dos seus trabalhos em função das atitudes dos seus alunos. Isso é útil, sobretudo, para que eles observem quais os aspectos que necessitam de modificações em relação ao ensino sobre o tema, e até mesmo procurem formas mais atrativas de abordar o assunto com os estudantes.

Curiosamente, apesar de a maior parte dos programas de prevenção atualmente existente aplicar os seus recursos nas escolas e nos professores, e serem baseados no modelo de informação científica (Canolleti, Soares, 2005), nitidamente aqueles não têm sido bem-sucedidos, pois os alunos, sobretudo nas escolas públicas, parecem não confiar na informação transmitida pelo professor (Sanchez et al., 2009).

\section{Possíveis modelos de prevenção na escola}

Os professores também foram questionados quanto aos possíveis modelos de programas de prevenção. As suas respostas refletiram que a maioria crê que seria prioritária a implementação de modelos que transmitissem informações científicas sobre o feito das drogas no organismo, assim como sobre as consequências do uso destas substâncias.

As sugestões dos professores, na sua essência, são semelhantes às propostas americanas de prevenção nas escolas, em que se utilizam modelos informativo-científicos (Cuijpers, 2002; Clayton, Cattarello, Johnstone, 1996). No entanto, nenhum deles cogitou a possibilidade de oferecer programas de habilidades sociais, comuns nas escolas europeias, os quais se destinam a desenvolver habilidades de relacionamento interpessoal, enfrentamento de dificuldades e desenvolvimento de perspectivas para o futuro, além de oferecer técnicas para aumentar a autoestima (Martín et al., 1999). Também não pensaram, como uma proposta alternativa, inclusive na prevenção primária, na aplicação de modelos de redução de danos, sugeridos por Moreira, Silveira, Andreoli (2006b). A proposta destes pesquisadores focou vários aspectos sobre o uso e o abuso de substâncias, especialmente na visão 
do indivíduo como um todo, sobre a qualidade de vida e os rompimentos com os preconceitos e as segregações (Moreira, Silveira, Andreoli (2006b).

Claro que o ideal seria criar um programa de prevenção inteiramente nacional, focado para a necessidade da população brasileira, visto que a importação de modelos educacionais tem fracassado devido à falta de alicerces culturais da nossa população (Cruz, 2002).

Mais de um terço dos professores mencionou que outros profissionais deveriam estar envolvidos neste tipo de atividade, alijando a sua responsabilidade em relação aos projetos sobre a prevenção do uso de drogas. Eles mencionaram os profissionais da saúde, os psicopedagogos, os assistentes sociais e os exusuários, como sendo os intervenientes necessários para uma atuação em conjunto para a realização de um programa de prevenção que produzisse efeitos satisfatórios. O discurso a seguir ilustra esta opinião:

“Eu acho que deveria ter, dentro da escola, palestras com profissionais especializados no assunto. Não nós, os professores, mas alguém que venha, faça palestras, dê um enfoque, que mostre mesmo e que vê com seriedade o problema que está acontecendo". (CF57PA)

Sodelli (2007) apontou para direção semelhante, quando disse que o professor, uma vez indagado ou pressionado pelos alunos sobre os reais problemas relacionados ao uso de drogas e às suas possíveis consequências, não se sentia preparado e com autoridade suficiente para discorrer sobre o assunto, garantindo que o profissional mais qualificado para este trabalho seria o da área da saúde - o médico ou o professor de biologia.

De um modo geral, a maioria dos professores sabia da necessidade e da importância de um programa cujo caráter seja preventivo. Eles relataram que seriam extremamente necessários: um bom material, um maior investimento na escola, um trabalho coletivo, sério, contínuo, constante, aberto a novas opiniões e a novos conhecimentos, com pessoas que se aprofundassem no assunto. Esta ideia, porém, implicaria o aumento da necessidade da disponibilidade e da motivação dos professores para que a mesma surtisse efeitos benéficos concretos. O presente trabalho trouxe à tona esta falha, ou seja, de que os professores estão conscientes da falta de informação dos alunos sobre o tema e, também, de que a escola é um importante veículo para proporcionar o debate e a aplicação de estratégias preventivas. Porém, eles não querem ser envolvidos diretamente nessa discussão, o que acaba contrariando a proposta atual da SENAD (Brasil, 2005), o qual propõe programas de redução da demanda de drogas por meio dos métodos de responsabilidade compartilhada, envolvendo diversas redes sociais, como a escola, a família, a comunidade e o governo. Se os professores não assumem o seu papel neste processo, acabam sobrecarregando as outras redes e enfraquecendo o processo preventivo.

Vale destacar também que qualquer estratégia preventiva a ser implantada em uma escola, necessita de tempo regular semanal para a sua execução. Não depende apenas de um professor decidir abordar a temática nas suas aulas, uma vez que este tem a obrigação de cumprir o currículo da sua disciplina dentro de uma carga horária em geral limitada, ficando sem tempo extra para tratar de assuntos não previstos. Da forma como o trabalho dos professores está organizado, qualquer trabalho preventivo dependerá de suporte por parte da direção da escola para adaptação do currículo da disciplina e da carga horária, fatores não relacionados à simples motivação do professor.

\section{Considerações finais}

Apesar dos dados relevantes que este estudo apresentou, houve limitações inerentes ao método que devem ser levadas em consideração. A metodologia qualitativa, utilizando-se de amostra intencional, não-aleatória, acabou por limitar as conclusões sobre a população investigada, não permitindo generalizar as mesmas em relação à população global ou, por tabela, inferir sobre outras populações.

Os entrevistados demonstraram possuir visões pouco científicas e um tanto deturpadas em relação ao tema drogas e aos seus usuários, baseadas no senso comum e em seminários pontuais de capacitação. Notadamente, estas capacitações não foram suficientes para formá-los como agentes multiplicadores de prevenção nas escolas. 
Apesar disto, os professores acreditam que a escola, devido ao seu caráter socializador, é o meio fundamental para a execução de programas de prevenção, além de ser o local onde os jovens podem ser formados e informados em relação ao tema. No entanto, devido ao seu despreparo, eles apenas conhecem e julgam eficaz o modelo de informação científica, não mencionando, nas suas preleções, a existência de modelos alternativos focados para o treinamento de habilidades sociais ou para o treinamento de resistência. Eles sentem-se responsáveis pela formação dos alunos em relação ao tema, porém, devido às suas limitações, eles preferem ser excluídos desse processo - fato que, na prática, tem sido impossível, já que a demanda do aluno em relação ao assunto recai sobre eles.

A abordagem do tema em sala de aula traz medo aos professores, pois além de passarem a informação para os seus alunos (tarefa para a qual eles já têm inúmeras dificuldades por conta da falta de conhecimento sobre o assunto), têm de avaliar a melhor forma de como a transmitir.

Consideram que qualquer programa de prevenção aplicado nas escolas deveria partir da iniciativa dos seus superiores (diretores e coordenadores pedagógicos), ser centralizado, específico, ou seja, baseado na realidade socioeconômica e cultural dos alunos, tendo o respaldo dos pais e a consultoria de profissionais da área das drogas.

Os autores deste trabalho acreditam que seja fundamental que os professores façam parte, como alicerce, de qualquer programa de prevenção desenvolvido nas escolas. A atual política nacional sobre drogas enfatiza que a prevenção ao uso de drogas deve basear-se na responsabilidade compartilhada. Não adiantaria apenas capacitar professores para lidarem com a temática na sala de aula, mas sim capacitá-los para pensarem programas que envolvam as diversas instâncias sociais. A solução também não pode ser transferir a solução do problema para os "especialistas" ou os profissionais da saúde. Um problema de origem multifatorial, sem dúvida, exige uma solução multifacetada. Os programas de prevenção, mesmo quando alocados nas escolas, exigem o envolvimento da família, da comunidade vizinha, da mídia, do governo, dos professores, dos funcionários e dos alunos, permitindo que cada segmento acione a sua rede social, oferecendo não apenas informação, mas recursos e atividades que permitam que o jovem tenha alternativas ao consumo de drogas. Não será um modelo único de prevenção que definirá o não-uso, mas talvez um modelo que agregue aquilo que há de mais dinâmico e positivo em cada programa. De qualquer forma, o professor, como formador de opinião de qualidade, é a chave fundamental neste processo.

\section{Colaboradores}

Tatiana Cristina Diniz Ferreira foi responsável pela coleta de dados, análise das entrevistas e redação da primeira versão do manuscrito. Zila van der Meer Sanchez supervisionou a coleta, a análise dos dados e a redação do manuscrito. Luciana Abeid Ribeiro redigiu a segunda versão do manuscrito e fez a revisão da literatura. Lúcio Garcia de Oliveira foi responsável pela discussão dos resultados e seleção dos discursos, e Solange Aparecida Nappo responsabilizou-se pela concepção teórica e supervisão geral.

\section{Referências}

ARMELIN, M.G. Prevenção às drogas na escola. O mundo da saúde, v.23, n.1, p.48-52, 1999.

BARDIN, L. Análise de conteúdo. 3.ed. Lisboa: Edições 70, 2004.

BIZZOTTO, A.; RODRIGUES, A.B. Nova lei sobre drogas: comentários à lei n.11.343, de 23 de agosto de 2006. Rio de Janeiro: Lúmen Júris, 2007.

BRASIL. Política Nacional Sobre Drogas. Brasília: CONAD, 2005. Disponível em: <http://www.obid.senad.gov.br/portais/OBID/biblioteca/documentos/ Legislacao/326979.pdf>. Acesso em: 30 jul. 2009.

BRYMAN, A.; BURGESS, R.G. Analyzing qualitative data. London: Routledge, 1999. 
BURT, M.R. Reasons to invest in adolescents. J. Adolesc. Health, v.31, n.6, p.136-52, 2002.

CANOLETTI, B.; SOARES, C.B. Programas de prevenção ao consumo de drogas no Brasil: uma análise da produção científica de 1991 a 2001. Interface - Comunic., Saude, Educ., v.9, n.16, p.115-29, 2005.

CARLINI-MARLATT, B. Estratégias preventivas nas escolas. In: SEIBEL, S.D.; TOSCANO JR., A. (Orgs.). Dependência de drogas. São Paulo: Atheneu, 2001. p.191-7.

CLAYTON, R.; CATTARELLO, A.M.; JOHNSTONE, B.M. The effectiveness of drug abuse resistance education (project DARE): 5-year follow-up results. Prev. Med., v.25, n.3, p.307-18, 1996.

CRESWELL, J.W. Qualitative inquiry and research design: choosing among five traditions. New York: Sage Publications, 1998.

CRUZ, A.R. A análise do discurso da prevenção do abuso de drogas. 2002. Tese (Doutorado) - Faculdade de Letras, Universidade Federal de Minas Gerais, Belo Horizonte. 2002

CUIJPERS, P. Effective ingredients of school-based drug prevention programs: a systematic review. Addict Behav., v.27, n.6, p.1009-23, 2002.

DEL RIO, M.C.; ALVAREZ, F.J. The harmful effects of drugs as perceived by the Spanish Public. Addiction, v.90, n.8, p.1113-6, 1995.

DENZIN, N.K.; LINCOLN, Y.S. (Eds.). The Sage handbook of qualitative research. 3.ed. California: Sage Publications, 2005.

FAGGIANO, F. et al. School-based prevention for illicit drugs' use. Cochrane Database Syst. Rev., n.2, CD003020, 2005.

FREIRE, P. Pedagogia da autonomia: saberes necessários à prática educativa. São Paulo: Paz e Terra, 1996.

GALDURÓZ, J.C.F.; NOTO, A.R.; CARLINI, E.A. V levantamento nacional sobre o consumo de drogas psicotrópicas entre estudantes do Ensino Fundamental e Médio da rede pública de ensino nas 27 capitais brasileiras. São Paulo: Cebrid, Universidade Federal de São Paulo, 2004.

KVALE, S. Interviews: an introduction to qualitative research Interviewing. Califórnia: Sage Publications, 1996.

LARANJEIRA, R. et al. I Levantamento nacional sobre os padrões de consumo de álcool na população brasileira. Brasília: Secretaria Nacional Antidrogas, 2007.

MARTÍN, M.A.L. et al. La prevención del consumo de drogas y la conducta antisocial en la escuela: análisis y evaluación de un programa. Madri: Universidade Santiago de Compostela, Ministerio de Educación y Cultura, Ministerio de Sanidad y Consumo, Ministerio del Interior, 1999.

MINAYO, M.C.S. O desafio do conhecimento: pesquisa qualitativa em Saúde. 8.ed. São Paulo: Hucitec, 2004.

MOREIRA, F.G. Prevenção do uso indevido de drogas: avaliação de conhecimentos e atitudes dos coordenadores pedagógicos das escolas públicas de ensino fundamental da cidade de São Paulo. 2005. Tese (Doutorado) - Universidade Federal de São Paulo, São Paulo. 2005

MOREIRA, F.G.; SILVEIRA, D.X.; ANDREOLI, S.B. Situações relacionadas ao uso indevido de drogas nas escolas públicas da cidade de São Paulo. Rev. Saude Publica, v.40, n.5, p.810-7, 2006a.

Redução de danos do uso indevido de drogas no contexto da escola promotora de saúde. Cienc. Saude Colet., v.11, n.3, p.807-16, 2006b. 
MUKOMA, W.; FLISHER, A.J. Evaluations of health promoting schools: a review of nine studies. Health Prom. Int., v.19, n.3, p.357-68, 2004.

NICASTRI, S.; RAMOS, S.P. Drug abuse is a preventable behavior: drug addiction is a treatable disease. J. Bras. Depend. Quím., v.2, supl.2, p.25-9, 2001.

NÓVOA, A. Os professores na virada do milênio: do excesso dos discursos à pobreza das práticas. Educ. Pesqui., v.25, n.1, p.11-20, 1999.

PATTON, M.Q. Qualitative evaluation and research methods. 3.ed. London: Sage Publications, 2002.

SANCHEZ, Z.V.D.M.; OLIVEIRA, L.G.; NAPPO, S.A. Razões para o não-uso de drogas ilícitas entre jovens em situação de risco. Rev. Saude Publica, v.39, n.4, p.599-605, 2005.

SANCHEZ, Z.V.D.M. et al. O papel da informação como medida preventiva ao uso de drogas entre jovens em situação de risco. Cienc. Saude Colet., v.15, n.2, p.621-30, 2009.

SCHENKER, M.; MINAYO, M.C.S. Fatores de risco e de proteção para o uso de drogas na Adolescência. Cienc. Saude Colet., v.10, n.3, p.707-17, 2005.

SCIVIOLETTO, S.; MORIHISA, R.S. Conceitos básicos em dependência de álcool e outras drogas na adolescência. J. Bras. Depend. Quím., v.2, n.1, p.30-3, 2001.

SOARES, C.B.; JACOBI, P.R. Adolescentes, drogas e aids: avaliação de um programa de prevenção escolar. Cad. Pesqui., v.109, s/n, p.213-37, 2000.

SODELLI, M. A aborgadem proibicionista em desconstrução: compreensão fenomenológica existencial do uso de drogas. Cienc. Saude Colet., v.15, n.3, p.637-44, 2010.

A prevenção em nova perspectiva: ações redutoras de vulnerabilidade ao uso nocivo de drogas. Rev. Port. Int. Saude Mental, v.9, n.2, p.3-58, 2007.

TAYLOR, S.J.; BODGAN, R. Introduction to qualitative research methods. New York: John Wiley \& Sons, 1998.

WORLD HEALTH ORGANIZATION - WHO. Qualitative research for health programmes. Geneva: Division of Mental Health, 1994.

FERREIRA, T.C.D. et al. Percepciones y actitudes de profesores de escuelas públicas y privadas ante el tema de las drogas. Interface - Comunic., Saude, Educ., v.14, n.34, p.551-62, jul./set. 2010.

En Brasil, pese a que los profesores se consideran como agentes potenciales para la prevención del uso de drogas, hace más de 20 años los programas escolares de prevención no han alcanzado los resultados esperados. Con la intención de auxiliar la identificación del origen del problema se evaluaron las percepciones/actitudes de profesores de la enseñanza fundamental y media de la ciudad brasileña de São Paulo con los cuales se realizaron entrevistas semi-estructuradas. Aunque estos profesionales se reconozcan como formadores de opinión, no se consideran suficientemente habilitados para tratar el tema con sus alumnos, ya por su falta de información, interés o habilidad para afrontar el asunto. En cuanto a la información sobre el tema se ha verificado baja percepción, del riesgo asociado a las drogas lícitas. Antes tales resultados se sugiere que los programas de prevención destinados al ambiente escolar se revisen con la participación de profesionales especializados.

Palabras clave: Prevención. Maestros. Estudiantes. Pesquisa cualitativa. Transtornos relacionados com substancias. Instituciones acadêmicas.

Recebido em 03/08/2009. Aprovado em 09/02/2010 